\title{
Evaluation of groundwater vulnerability in El-Bahariya Oasis, Western Desert, Egypt, using modelling and GIS techniques: A case study
}

\author{
M H MASOUD ${ }^{1,2}$ and M M El Osta ${ }^{3, *}$ \\ ${ }^{1}$ Hydrology Department, Desert Research Centre, El Matarya, Cairo, Egypt. \\ ${ }^{2}$ Water Research Centre, King Abdulaziz University, Jeddah, Saudi Arabia. \\ ${ }^{3}$ Geology Department, Faculty of Science, Damanhour University, Damanhour, Egypt. \\ ${ }^{*}$ Corresponding author.e-mail: drmagedelosta.edu.alex@hotmail.com
}

The Nubian Sandstone Aquifer (NSSA) is the main groundwater resource of the El-Bahariya Oasis, which is located in the middle of the Western Desert of Egypt. This aquifer is composed mainly of continental clastic sediments of sandstone with shale and clay intercalations of saturated thickness ranging between 100 and $1500 \mathrm{~m}$. Vulnerability assessment to delineate areas that are more susceptible to contamination from anthropogenic sources has become an important element for sustainable resources management and land use planning. Accordingly, this research aims to estimate the vulnerability of NSSA by applying the DRASTIC model as well as utilising sensitivity analyses to evaluate the relative importance of the model parameters for aquifer vulnerability in the study area. The main objective is to demonstrate the combined use of the DRASTIC and the GIS techniques as an effective method for groundwater pollution risk assessment, and mapping the areas that are prone to deterioration of groundwater quality and quantity. Based on DRASTIC index (DI) values, a groundwater vulnerability map was produced using the GIS. The aquifer analysis in the study area highlighted the following key points: the northeastern and western parts of the NSSA were dominated by 'High' vulnerability classes while the northwestern and southeastern parts were characterised by 'Medium' vulnerability classes. The elevated central part of the study area displayed 'Low' aquifer vulnerability. The vulnerability map shows a relatively greater risk imposed on the northeastern part of the NSSA due to the larger pollution potential of intensive vegetable cultivation. Depth-to-water, topography and hydraulic conductivity parameters were found to be more effective in assessing aquifer vulnerability.

\section{Introduction}

Groundwater is susceptible to anthropogenic activity resulting from urbanisation, increase in populations, land reclamation, increase of agricultural activities and lack of proper sewage and irrigationdrainage systems. These factors will cause considerable deterioration of groundwater quality and quantity (UNESCO 1998; Polemio et al. 2009). According to Rahman (2008), groundwater is sensitive to the geological and hydrological setting of the area, where these conditions control the time and directions of flow, and the water quality (Prior et al. 2003). The idea of the vulnerability of groundwater to the external pollution was first discussed by Margat (1968) following which this

Keywords. El-Bahariya Oasis; Nubian Sandstone Aquifer; vulnerability of groundwater; DRASTIC model; GIS technique. 
concept was further developed by many authors (Aller et al. 1987; Civita et al. 1994; Polemio et al. 2009; Sener et al. 2009). SNIFFER (Scotland and Ireland Forum for Environmental Research) (2004) reported that groundwater vulnerability to contamination is defined as the tendency or likelihood for pollutants to reach a water table after discharging at the ground surface. Vulnerability mapping is the process of assessing the sensitivity of water resources to their surrounding environments. The resulting maps are effective and helpful for regional planning and decision making (Rahman 2008).

According to the Ministry of Public Works and Water Resources (1998), prior to 1963, the only water sources available for cultivation and domestic uses in the El-Bahariya Oasis were the shallow and natural springs. As a result of increasing population and cultivated areas, deep well drilling was initiated in 1963. The piezometer head of the aquifer during the period 1963-1970, declined to an annual rate of about $1.2 \mathrm{~m}$. Nowadays, many of the deep artesian wells have become pumped wells; rather than being shallow naturally flowing, the wells have become dry due to the intensive groundwater extraction from the Nubian Sandstone Aquifer. Currently, the total number of groundwater wells is about 905 (811 wells have a total depth less than $300 \mathrm{~m}$, while 94 of them are more than 700 $m$ deep) with the entire annual extraction about $100.2 \times 10^{6} \mathrm{~m}^{3}$ (RIGW 2010). It is predicted that the expected drawdown of the El-Bahariya Oasis will range from 3 to $26 \mathrm{~m}$ with minimum water allocation through the next 25 years (El Hossary 2013). Hence, this research deals with the evaluation of groundwater vulnerability in the study area using the DRASTIC model and GIS techniques for mapping areas that are prone to deterioration of groundwater quality and quantity. Based on the U.S. Environmental Protection Agency (1985) (Aller et al. 1987), the DRASTIC model is an experimental tool used to assess the groundwater vulnerability. The DRASTIC model includes two essential sections: (1) development of hydrogeological maps and (2) application of a numerical program of relative ranking to the hydrogeological parameters (Lee 2003; Alwathaf and El Mansouri 2011).

\section{Research area}

\subsection{Location and geomorphology}

The El-Bahariya Oasis is a natural oval depression located in the middle of the Western Desert of Egypt in the NE-SW direction and covers an area of approximately $2700 \mathrm{~km}^{2}$. It is located about $375 \mathrm{~km}$ to the southwest of Cairo between longitudes $28^{\circ} 30^{\prime}-29^{\circ} 10^{\prime} \mathrm{E}$ and latitudes $27^{\circ} 42^{\prime}-28^{\circ} 35^{\prime} \mathrm{N}$ (figure 1). The El-Bahariya Oasis is an important natural depression in Egypt and is characterised by a hyper-arid climatic condition. It receives very little annual rainfall - less than $50 \mathrm{~mm}$ per year. This oasis is a very important area from the standpoint of economics, industries, agriculture and tourism.

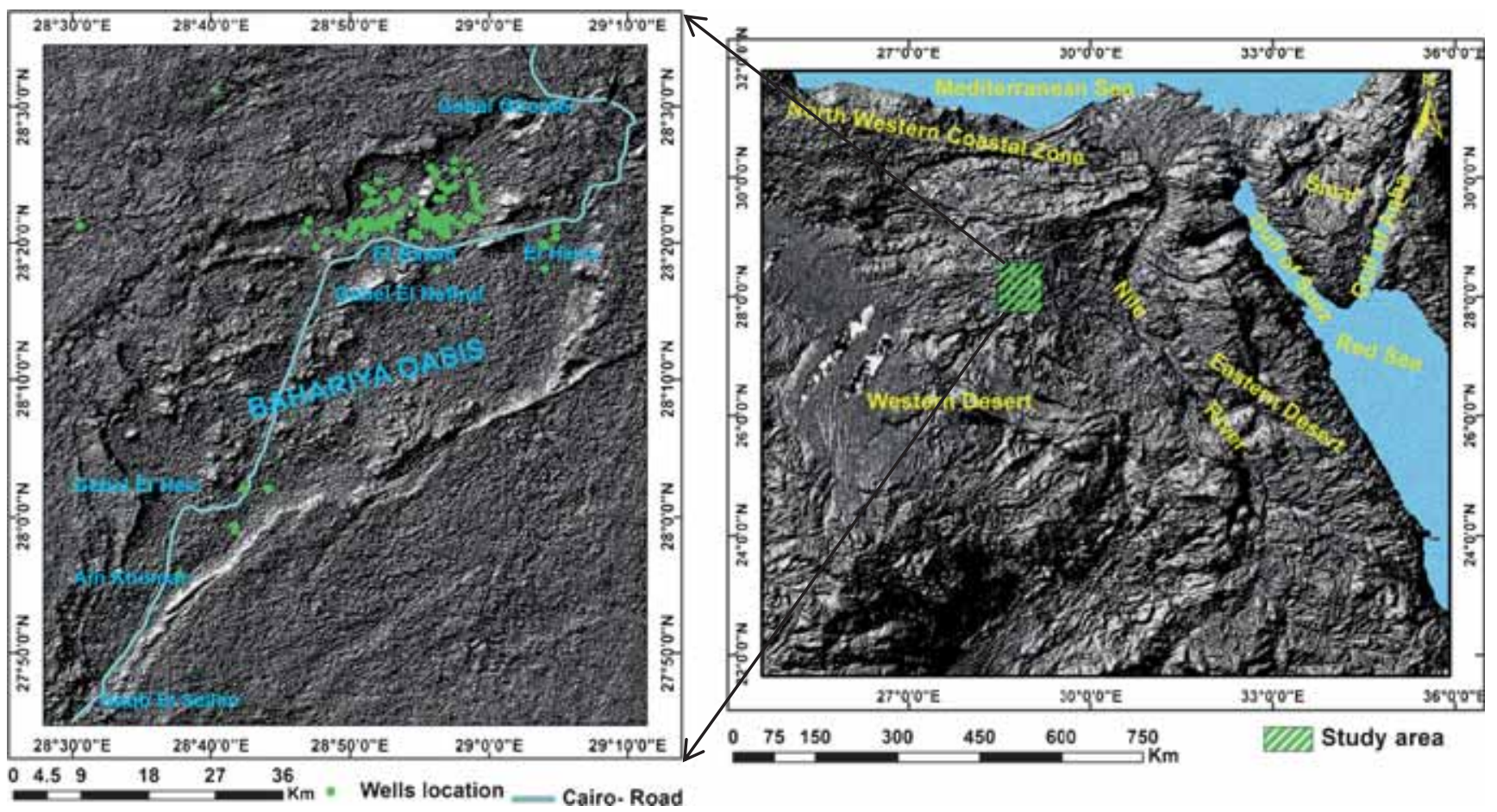

Figure 1. Location map of the study area. 
The main water resource in this area is the groundwater stored within the Nubian Sandstone Aquifer (NSSA). The NSSA is characterised with a bulk thickness ranging from 100 to $1800 \mathrm{~m}$, a transmissivity which reaches to $17000 \mathrm{~m}^{2} /$ day and hydraulic conductivity ranging from 2.8 to $32 \mathrm{~m}$ /day with an average value of about $9.5 \mathrm{~m} /$ day (Ministry of Public Works and Water Resources 1998).

The El-Bahariya Oasis, initially developed during the lower Eocene due to tectonic movements, is now occupied by a major depression floor dotted by several isolated residual hills and is surrounded by escarpments from the northern and eastern parts (Hamdan 2012). Overall, the ElBaharyia Oasis is characterised by the following geomorphological units (figure 2):

- A depression, which is oval shaped and characterised by low relief, where the elevation ranges from 57 to $200 \mathrm{~m}$ AMSL. The bottom of the depression is carved into the clastic Upper Cretaceous of El-Bahariya Formation.

- Surrounding escarpment is the edge which separates the depression and plateau and is represented by Upper Cretaceous of Campanian age and El Hiez Formation.

- Plateau: El-Bahariya depression is excavated in Thebes Group of the Lower Tertiary. The plateau surface is rugged with a northward slope. The

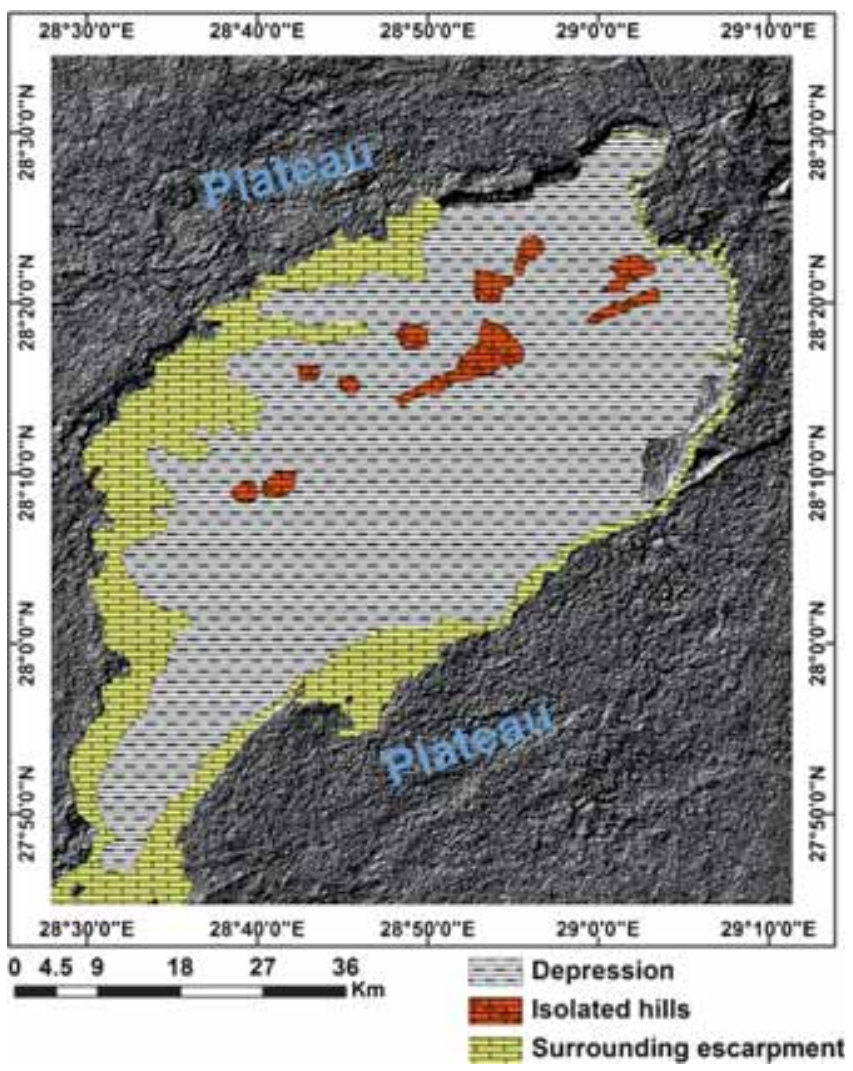

Figure 2. Geomorphological map of the study area. plateau surface is dissected by long and short dry wadis draining into the excavated depression (Hamdan and Sawires 2013).

\subsection{Geological setting}

According to Hamdan and Sawires (2013), the geological units of the study area are classified from top to bottom, as follows (figure 3):

- Quaternary: These rocks are composed of various deposits such as Aeolian sands of dispersed sand dunes in the depression and on the surface of the plateau, salt deposits and sabkhas which are located around the cultivated areas, and Playa deposits which are composed of fine sand, silt and dark-brown clay with evaporites.

- Tertiary: These rocks range from Lower Tertiary (Thebes group) to Lower Miocene. The Lower Miocene is composed of some scattered of volcanic basaltic hills; Middle Tertiary, which is composed of Hamra Formations (fossiliferous limestone intercalated with clastic beds) and Qazzun Formation (white Nummulitic carbonate rocks of limestone and dolostone); and Lower Tertiary, which is composed of the Naqb Formation (Thebes group) consisting pink to violet Nummulitic dolostone and limestone.

- Cretaceous: These rocks are represented by a multi-layered section, of a thickness of more than $660 \mathrm{~m}$, overlying the Cambrian deposits and are classified into four formations from top to bottom, as follows:

(a) Khoman Formation of the Maastrichtian age, which consists of chalky limestone reaching $45 \mathrm{~m}$ in thickness.

(b) El Hefhuf Formation of the Campanian age which consists of dolostone beds intercalated with sandstone and sandy clay beds.

(c) El Heiz Formation of the Upper Cenomanian age, which consists of fossiliferous limestone, sandstone, shale and marls with a maximum thickness reaching up to $30 \mathrm{~m}$.

(d) Bahariya Formation of the Lower Cenomanian, which consists of fluviatile sandstone and covers the floor of the El-Bahariya depression with a thickness of about $70.5 \mathrm{~m}$.

\subsection{Structural setting}

The El-Bahariya Oasis is considered to be a range of eroded anticline folds formed during the Syrian arc fold system, which has the NE-SW trend. The axis of this anticline fold extends from Gebel Ghorabi in the north towards the southwest direction, crossing the central isolated hills of the depression (Shukri 1954; Hamdan 2012). 


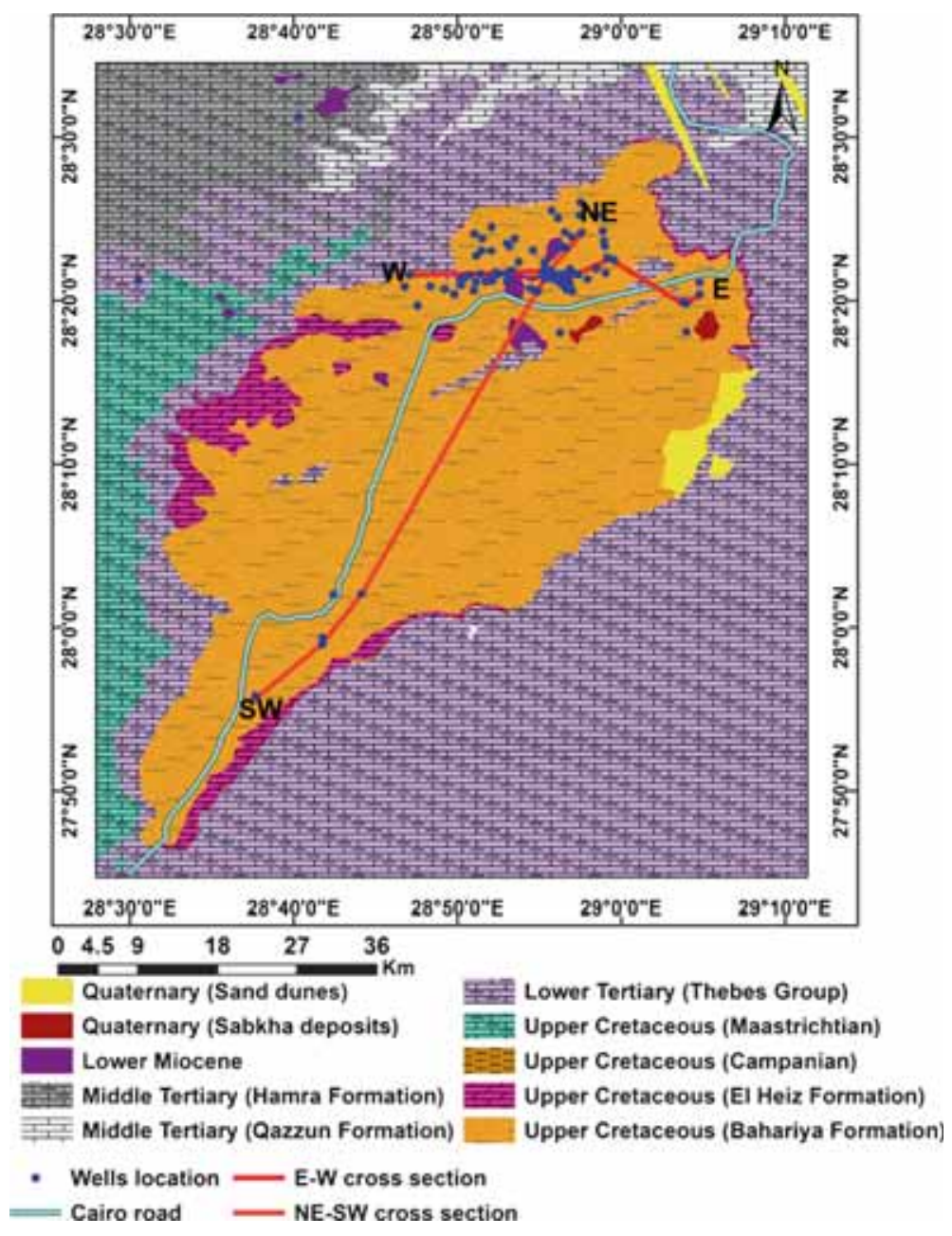

Figure 3. Geological map of the study area (after Canoco 1987).

Table 1. Structural lineaments data of the study area.

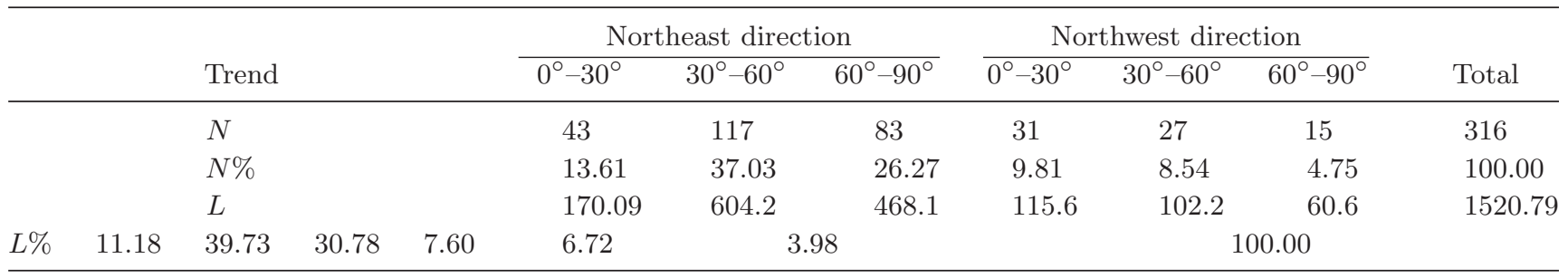

where $N$ is the number of lineaments, $N \%$ is the percentage of lineaments, $L$ is the length of lineaments and $L \%$ is the percentage of lineaments.

Lineaments are common structural features in the study area; these lineaments are surface aspects of structurally controlled features such as faults, fractures, joints and straight course of dry streams (i.e., wadis). Systemic lineaments are usually analysed using number frequency (number of lineaments per unit of area) or density (length of lineaments per unit of area) using the azimuth diagram (Mostafa and Zakir 1996; Zakir et al. 1999) and rose diagrams (Karnieli et al. 1996). The structural lineaments of the study area were analysed and the azimuth-frequency diagrams were created as shown in table 1 and figure 4 . Results show that the study area is affected by the structures creating horsts and grabens (depression) and most of these lineaments are common in the surrounding plateau while some rare major lineaments have occurred in the depression (figure 4). The lineament frequency and density in the study area are about 0.05 and $0.23 \mathrm{~km}^{-1}$, respectively. They are oriented in the NE-SW direction (77\%) with the mean vector about $34^{\circ} \mathrm{NE}$. The direction of the lineaments mostly correlates with the direction of the main-stream network, especially the 


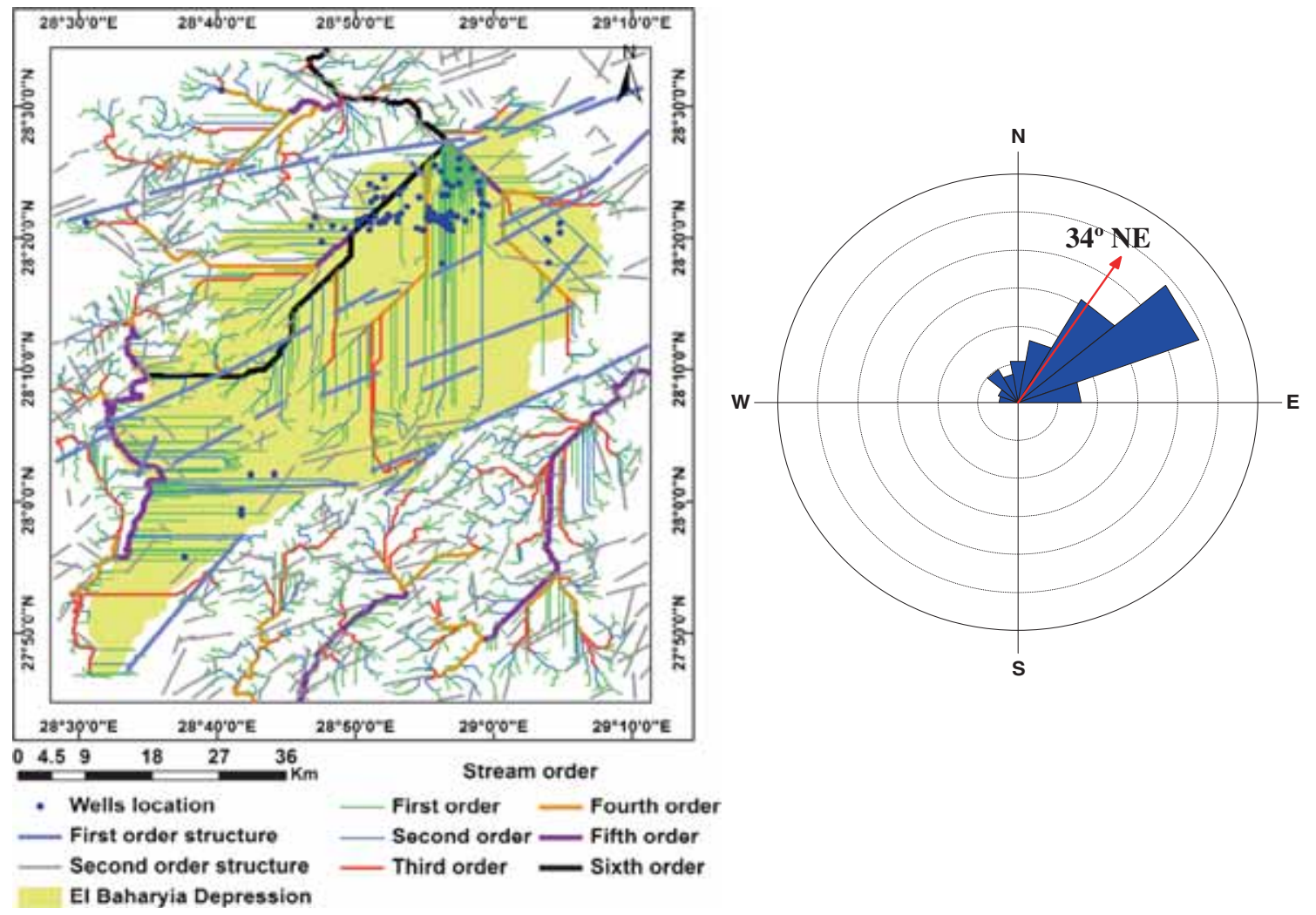

Figure 4. Lineament structural and stream order map and rose diagram of the study area.

higher orders (4th, 5th, and 6th order), as shown in figure 4.

Finally, structures of faults, joints, fractures, straight course of dry streams and folds are common in El-Bahariya Oasis. These elements are of high importance for vulnerability assessment (Al-Fawwaz 2010).

\subsection{Hydrogeological setting}

Generally, the Nubian Sandstone Aquifer (NSSA) is considered the main source of water in the El-Bahariya Oasis. This aquifer is composed of continental clastic sediments, essentially sandstone intercalation with shale and clay. Regionally, the NSSA is a multi-layered artesian aquifer with a thickness reaching $1800 \mathrm{~m}$ and acts as a hydrogeologic system which is hydraulically connected with surrounding and underlying water-bearing formations through faults or channels that allow upward leakage (Parsons 1962; Ezzat 1974; Euro and Pacer 1983; El Bastawesy et al. 2010). Locally, the NSSA in the El-Bahariya Oasis is composed of two aquifer systems (Khalifa 2006). The first one is the PostNSSA System, which extends towards the north of latitude 26 in the Western Desert of Egypt (CEDARE 2001). The second is the NSSA system and is composed of continental clastic sediments of sandstone intercalated with shale and clays
(Himida 1964; Diab 1972) and is considered the main water source in the area under investigation. The transmissivity of the NSSA is varied - from medium to high aquifer potentiality, which ranges from 236 to $3045 \mathrm{~m}^{2}$ /day, increasing gradually from south to north (Hamdan 2012).

Depending on 15 available well logs that are scattered in the study area, two hydrogeological cross sections from east to west and from the northeast to southwest were constructed as shown in figures 3,5 and 6 . From these sections, the following points are of special interest:

- The NSSA is composed of clastic sediments of mainly fine to medium sandstone with darkish grey shale intercalations. The thickness of this aquifer ranges from $317 \mathrm{~m}$ in the southwest to more than $1000 \mathrm{~m}$ in the northwest.

- The NSSA is highly dissected by a number of major faults in the area covering the El-Bahariya depression and surrounding plateau. This faulting system is responsible for the thickening and thinning, uplifting and down-blocking of the main aquifer.

- The piezometer heads in the NSSA are affected considerably by the faulting system.

Based on the analyses of 26 long duration pumping test's representative for the NSSA, the hydraulic parameters could be determined as shown in 


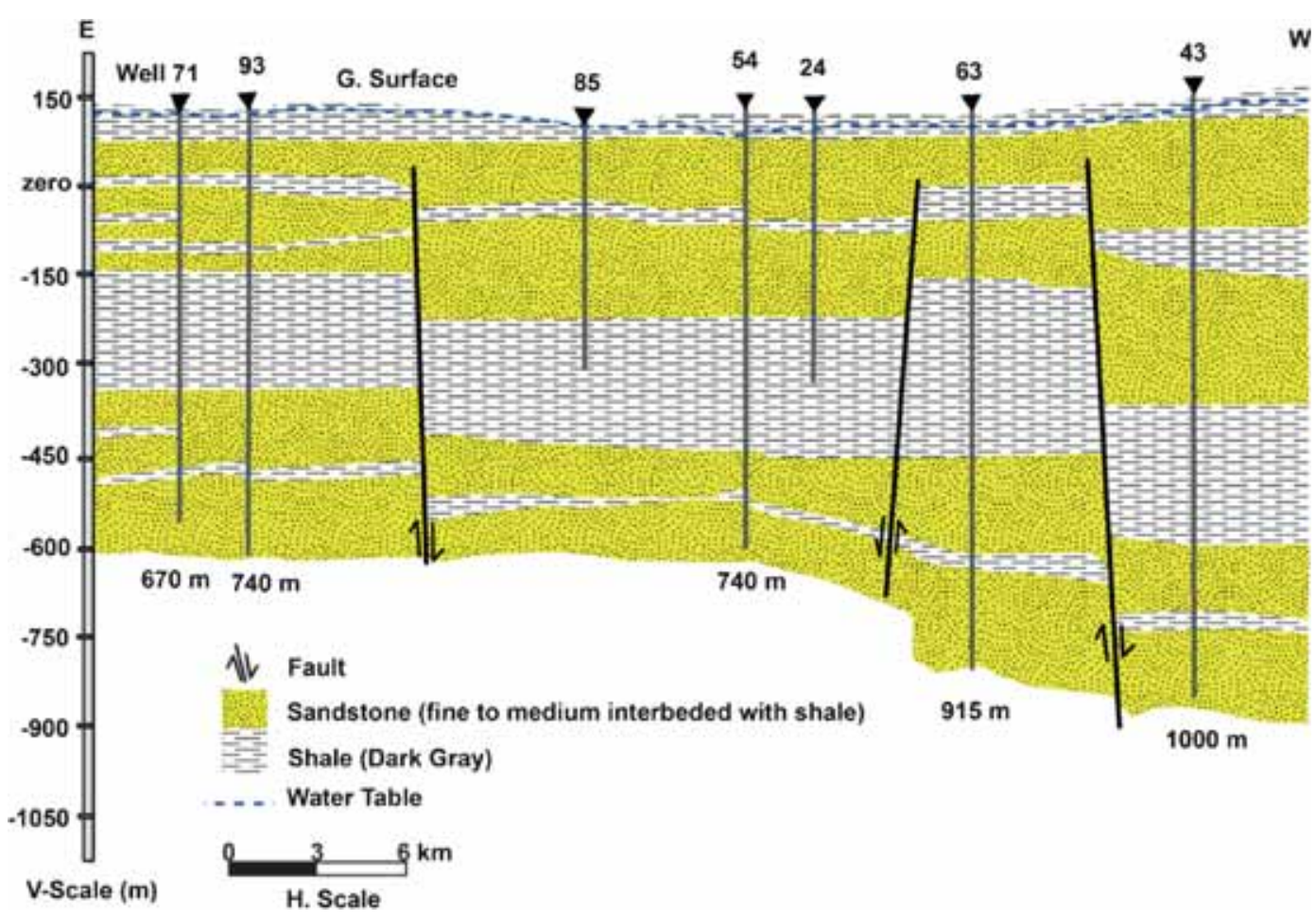

Figure 5. Hydrogeological cross section (E-W) of the study area.

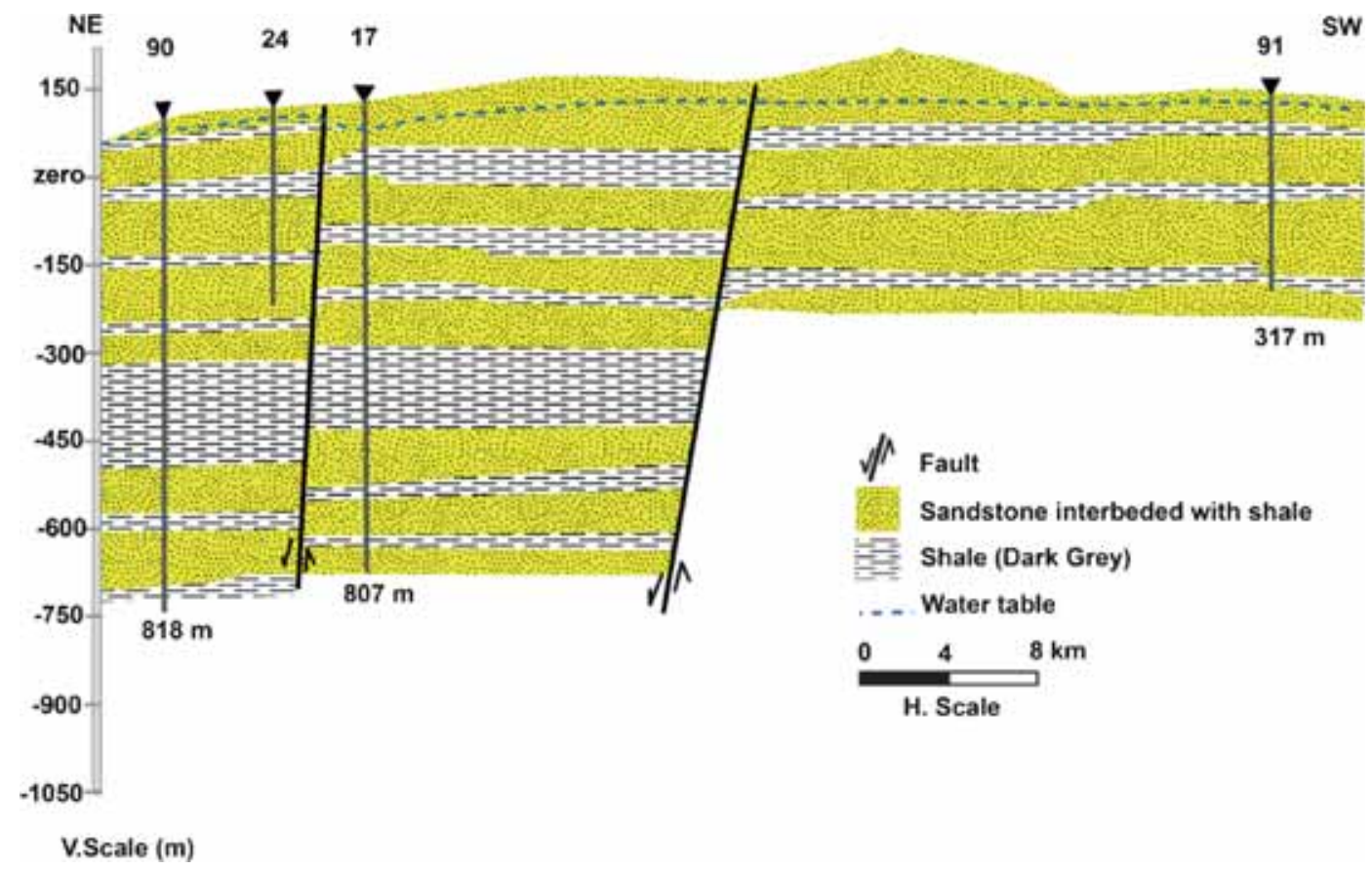

Figure 6. Hydrogeological cross section (NE-SW) of the study area.

table 2. The transmissivity of the NSSA ranges from 190.89 to $1750 \mathrm{~m}^{2}$ /day with a mean value of $970.45 \mathrm{~m}^{2} /$ day, while the hydraulic conductivity ranges from 1.12 to $24.9 \mathrm{~m} /$ day with a mean value of $13.1 \mathrm{~m} /$ day. The groundwater flow of the NSSA in the El-Bahariya depression as well as in other depressions of the Western Desert of Egypt is controlled by recharge and discharge conditions and by the variation of the aquifer parameters as well as by the faulting system. The potentiometer head contour map for the year 2011 (figure 7), indicates that the flow lines are directed from southwest to 
Table 2. Hydraulic parameters of the NSSA according to Theis (1935).

\begin{tabular}{|c|c|c|}
\hline Well no. & $\begin{array}{l}\text { Transmissivity } \\
(\mathrm{T})\left(\mathrm{m}^{2} / \text { day }\right)\end{array}$ & $\begin{array}{l}\text { H. conductivity } \\
(\mathrm{K})(\mathrm{m} / \text { day })\end{array}$ \\
\hline 4 & 1750 & 16.7 \\
\hline 7 & 532.8 & 2.96 \\
\hline 10 & 238 & 4.5 \\
\hline 15 & 289 & 3.2 \\
\hline 16 & 390 & 3.9 \\
\hline 17 & 677.8 & 3.389 \\
\hline 23 & 2448 & 24.9 \\
\hline 24 & 305.57 & 1.89 \\
\hline 26 & 625 & 6.2 \\
\hline 37 & 446.4 & 2.97 \\
\hline 40 & 410 & 2.8 \\
\hline 41 & 1460 & 18.4 \\
\hline 43 & 286.47 & 1.59 \\
\hline 49 & 442 & 3.4 \\
\hline 63 & 401.745 & 2.231 \\
\hline 64 & 190.89 & 1.12 \\
\hline 65 & 2361 & 15.74 \\
\hline 70 & 344.22 & 2.02 \\
\hline 71 & 305.57 & 1.909 \\
\hline 77 & 341.6 & 2.277 \\
\hline 89 & 313.38 & 2.41 \\
\hline 90 & 366.49 & 1.83 \\
\hline 91 & 305.57 & 2.18 \\
\hline 92 & 286.47 & 1.9 \\
\hline 93 & 343.77 & 1.637 \\
\hline 94 & 361.57 & 2.008 \\
\hline
\end{tabular}

northeast of the oasis as a general flow, while in the northern sector it becomes from east and west to the $\mathrm{Al}$ Bawiti area as a result of intensive groundwater extraction in this area. The flow direction in the southern sector is concentrated from northwest to southeast (figure 7), which clearly coincides with the ground surface drainage networks of the study area (figure 11).

Based on the available six wells that have a history piezometer head started from 1963 until 2011, the behaviour of the piezometric head with time was plotted (figure 8). The head of the NSSA is noticeably depleted from year to year, with rates ranging from 0.44 to $0.88 \mathrm{~m}$ per year and a mean value equalling $0.73 \mathrm{~m}$ annually. This lowering is very serious since it has resulted in the pumping of groundwater from about 100 pumped wells. On the other hand, the satellite images for the Bahariya Oasis showed a significant increase of agricultural areas during the period 1984-2011, but the water ponds occupying the main playa near Al Bawiti have notably expanded over large surface areas and several fields in their surroundings have been submerged (figures 9 and 10). However, large areas of the depressions have already been irrigated, but

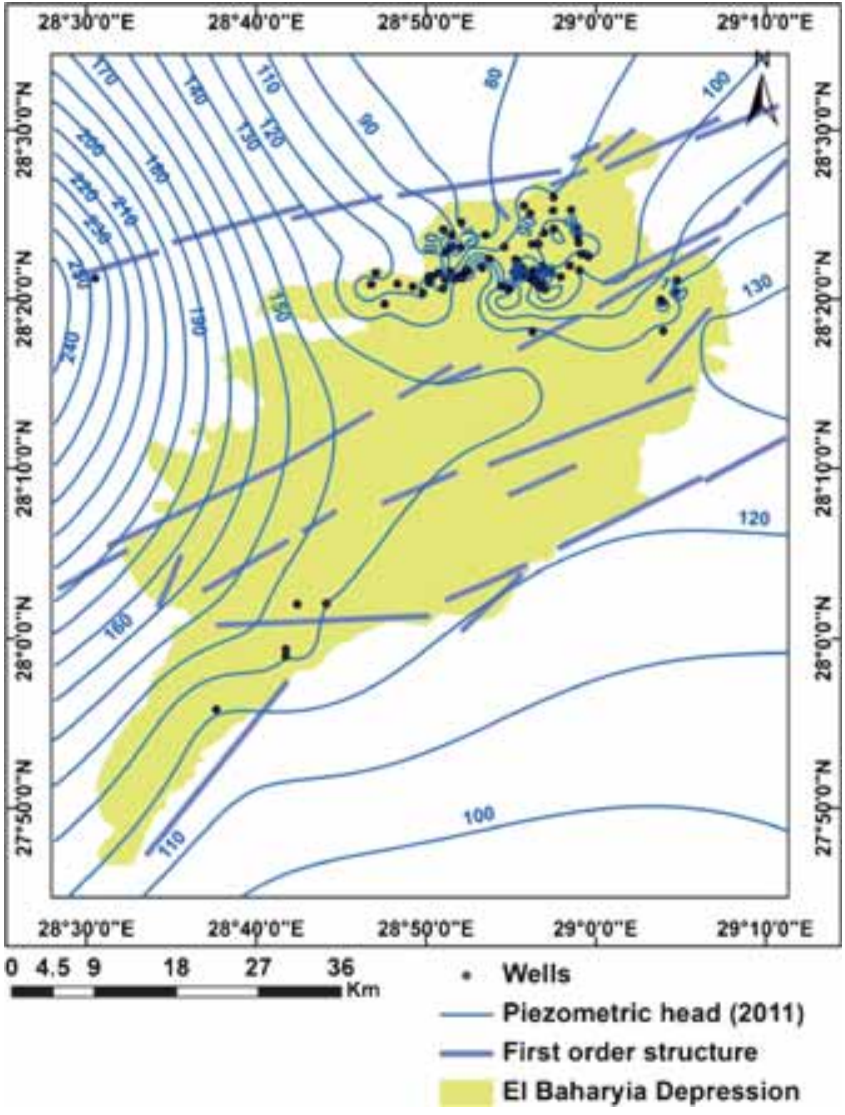

Figure 7. Potentiometric head contour map in the study area.

the drainages of cultivated areas were ignored as it was generally believed that the natural drainage capacity of the deep sandy soil profiles is efficient in controlling rising soil water tables and salt accumulation in these areas. The interpretation of satellite images and field observations showed that the cultivation of large areas in closed drainage basins has developed extensive tracts of waterlogging and water ponds on the low playa surfaces. Most of the waterlogged areas are distributed in a unique pattern resembling channels of drainage basins. Although most of the drainage networks of the ElBaharyia depression (which were formed during the Quaternary wet pluvial) are of poor surface expression due to the prevailing aridity, they are now buried by sand sheets (El Bastawesy et al. 2013). The automatically extracted surface drainage networks from the DEM (figure 11) are nearly similar to the extent of seepage and waterlogging pattern within the freshly cultivated fields, as well as the stream network of groundwater flow direction in the study area (figure 12). This similarity is significant to delineate the poorly expressed drainage networks, select new optimum locations for agricultural development as well as for drilling new water wells in the El-Bahariya Oasis. The similarity between rose diagrams of the lineaments and 


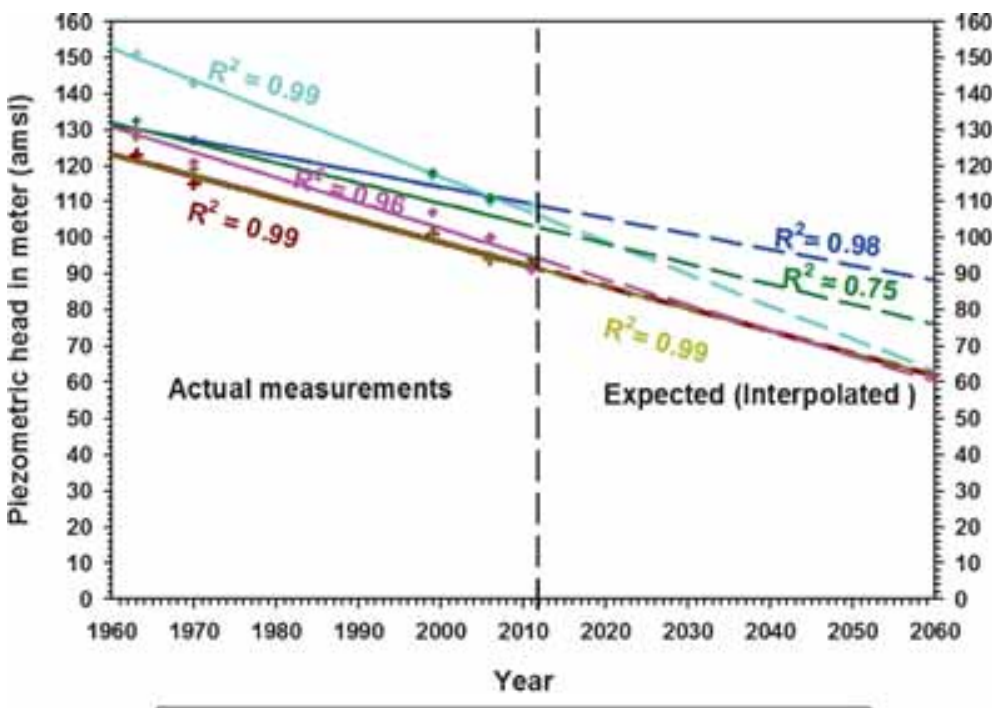

Piezometric head of well No. 65 with time
- Fitting curve of piezometric head of well No, 65 with time
Piezometric head of well No. 80 with time
Fitting curve of piezometric head of well No. 80 with time
Piezometric head of well No. 15 with time
- Fitting curve of well No, 15 with time
Piezometric head of well No. 40 with time
- Fitting curve of piezometric head of well No. 40 with time
Piezometric head of well No. 41 with time
- Fitting curve of piezometric head of well No, 41 with time
Piezometric head of well 42 with time

Figure 8. Depletion rate of piezometric head in the study area (2011).
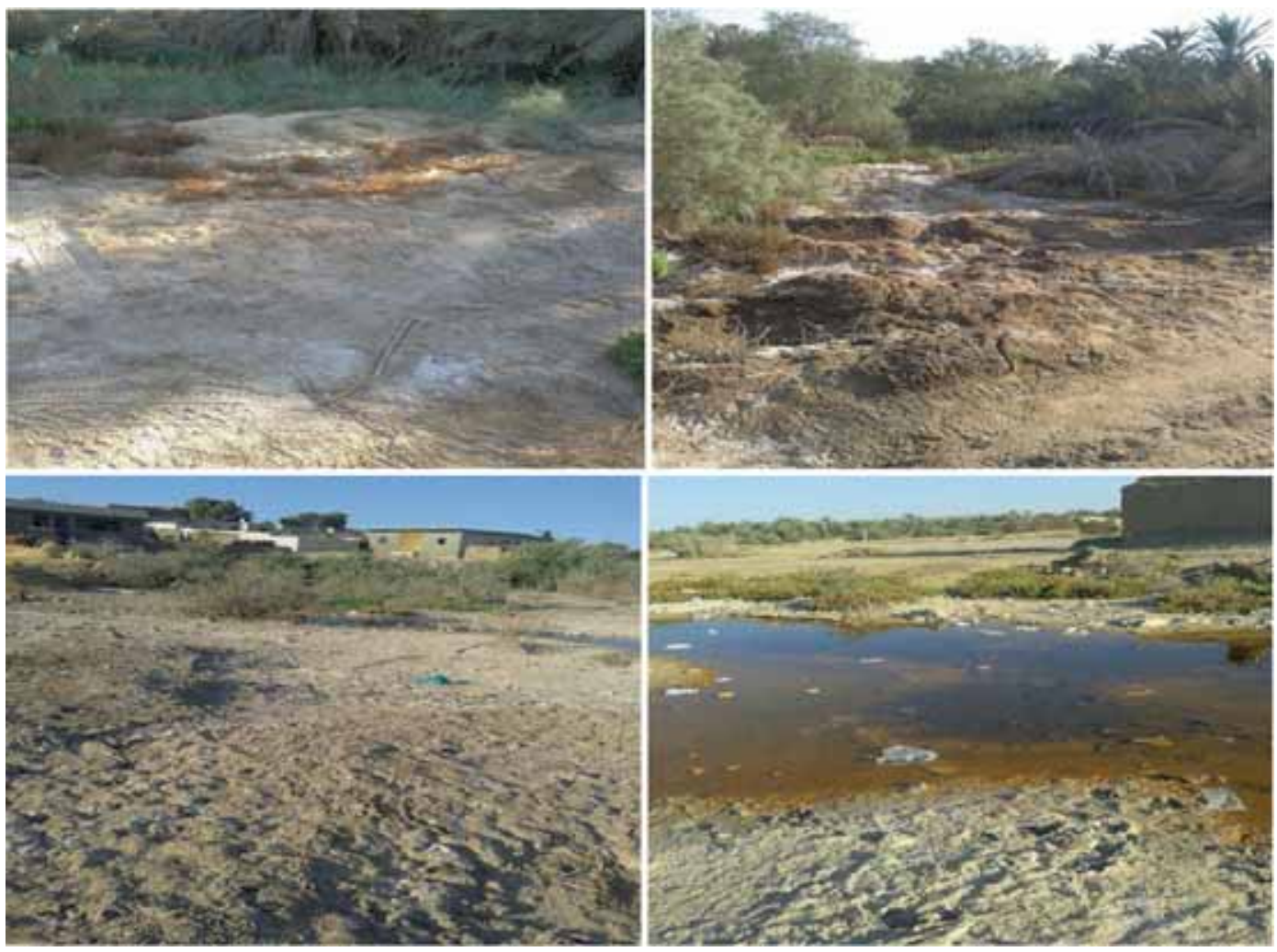

Figure 9. Field photos show the development of waterlogging within the El-Bahariya Oasis and the growth of plant and shrub species distinctive to saline and waterlogged soil. 

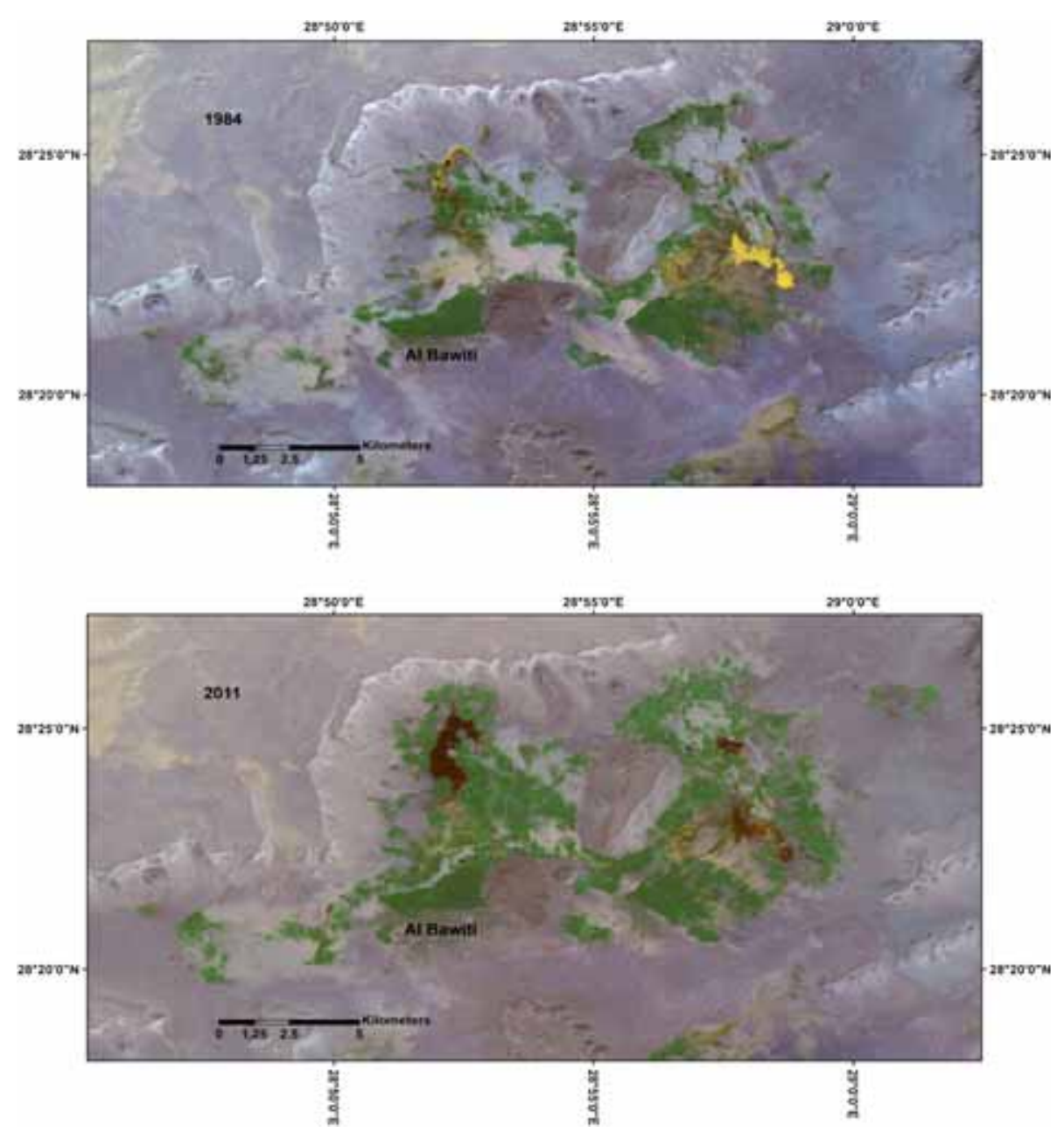

Figure 10. The cultivated area (green) changes within El-Baharyia Oasis between 1984 and 2011. Note the development of water ponds (brown) (El Bastawesy et al. 2013).

piezometric groundwater flow direction (figures 4 and 12 , respectively) indicated the following:

- The origin of the concerned aquifer is synchronised with the formation of the surface terrain of the study area.

- The surface drainage streams and the NSSA were subjected to the same geologic structure.

- The water flows under pressure through faults and fractures in the direction of the geologic structures.

- The study area is considerably influenced by the Syrian arc fold system, which has a main trend of NE-SW.

\section{Materials and methods}

The worldwide concern about groundwater contamination problems has resulted in the development of the concept of groundwater vulnerability. This concept depends on the assessment and representation of various attributes such as vadose zone characteristics, aquifer depth and the amount of recharge (Murray and Rogers 1999). Groundwater vulnerability maps are important tools to draw the attention of land use planners to existing problems. It is also used to anticipate the movement of pollutants in the soil, allowing planners to modify the potential occurrence of harmful conditions, such as groundwater contamination, before serious impacts occur (Murray and Rogers 1999).

In the present study, an integration of the DRASTIC model and the ArcView GIS (9.2) technique was used to evaluate the groundwater vulnerability of the NSSA in the concerned area. The DRASTIC model is an overlay and indexing method that is widely used to assess intrinsic groundwater vulnerability, and was developed by the U.S. Environmental Protection Agency (EPA) to evaluate groundwater pollution potential for the entire United States (Aller et al. 1987). It is based on the concept of the hydrogeological setting which is defined as a composite description of all the major geologic and hydrologic factors that affect and control the groundwater movement into, through, and out of an area (Aller et al. 1987). 

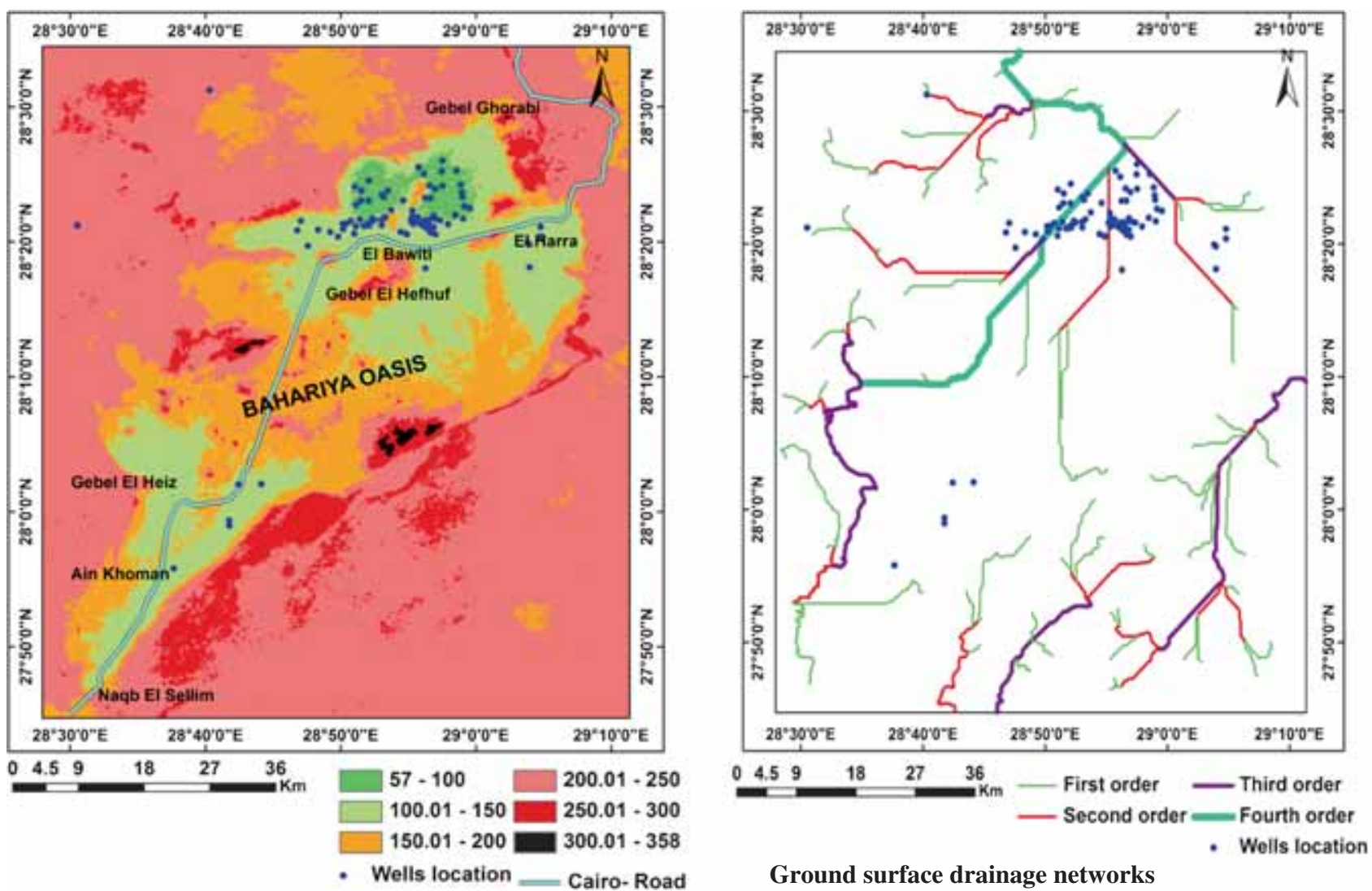

Figure 11. The DEM and the automatically extracted surface drainage networks for the cultivated catchments within the study area.
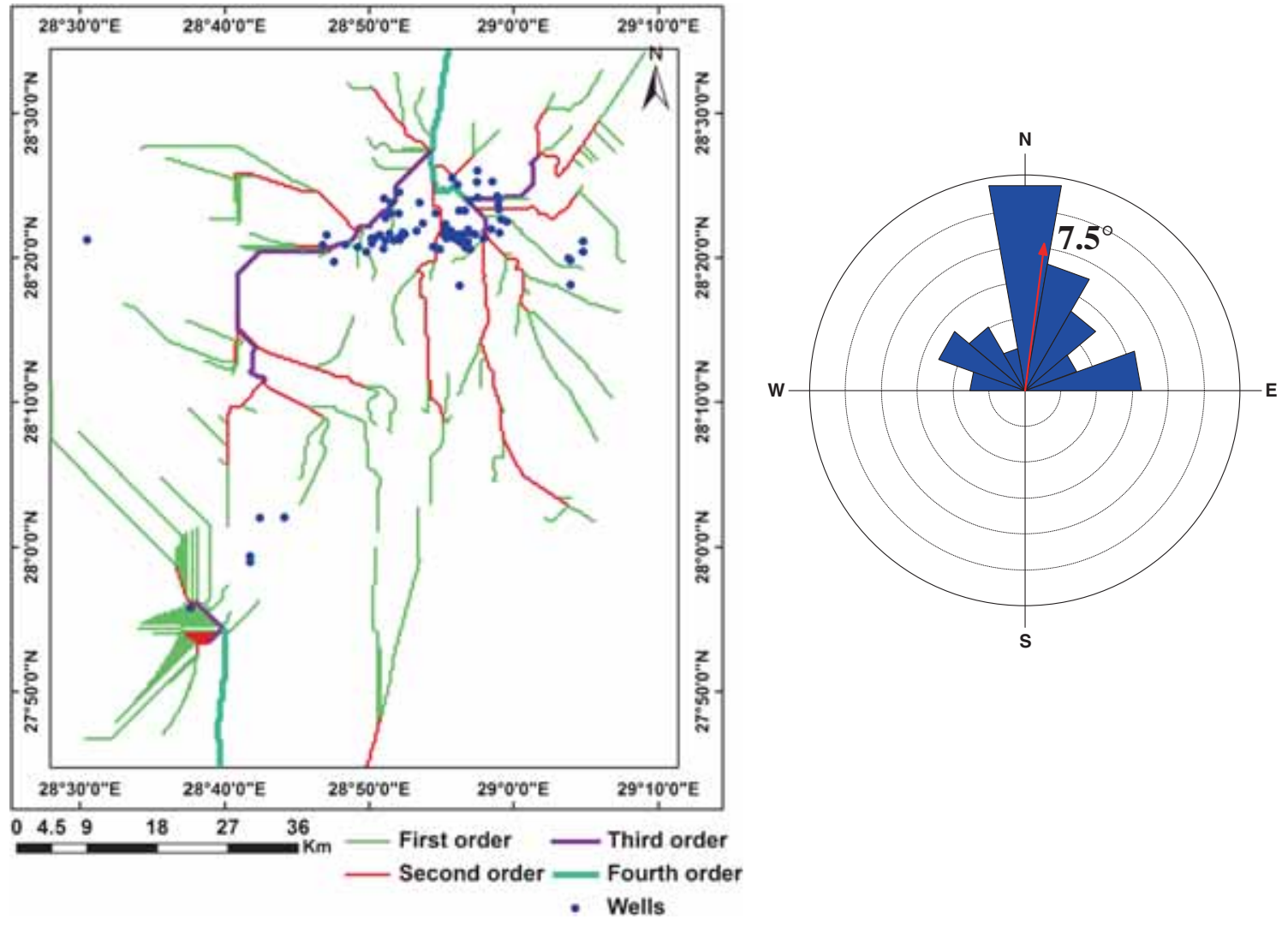

Figure 12. The stream network of groundwater flow direction of the study area and its rose diagram. 
The term 'DRASTIC' comes from the abbreviation of the seven parameters that are involved in the model. These parameters are depth-to-water, recharge of network area, aquifer matrix, soil media, topography, impact of the vadose zone and hydraulic conductivity. The model yields a numerical index that is derived from ratings and weights assigned to the seven model parameters. The significant media types or classes of each parameter represent the ranges, which are rated from 1 to 10, based on their corresponding effect on the aquifer vulnerability (table 3 ). The seven parameters are subsequently assigned weights ranging from 1 to 5 reflecting their relative importance. The DRASTIC index is later computed applying a linear combination of all factors according to the following equation:

$$
\begin{aligned}
& \text { DRASTIC index }=D_{\mathrm{r}} D_{\mathrm{w}}+R_{\mathrm{r}} R_{\mathrm{w}}+A_{\mathrm{r}} A_{\mathrm{w}} \\
& \quad+S_{\mathrm{r}} S_{\mathrm{w}}+T_{\mathrm{r}} T_{\mathrm{w}}+I_{\mathrm{r}} I_{\mathrm{w}}+C_{\mathrm{r}} C_{\mathrm{w}}
\end{aligned}
$$

where $D, R, A, S, T, I$, and $C$ are the seven parameters and the subscripts ' $\mathrm{r}$ ' and ' $\mathrm{w}$ ' are the corresponding rating and weights, respectively. This model was selected based on the following considerations. DRASTIC uses these parameters to compute the vulnerability index, which ensures the best representation of the hydrogeological setting. The numerical ratings and weights, which were established using the Delphi technique (Aller et al. 1987, modified Piscopo 2001), are well-defined and are used worldwide. This makes the model suitable for producing comparable vulnerability maps on a regional scale Each DRASTIC feature has assigned a weight relative to each other according to their importance from 1 to 5 ; the least significant being allocated 1 , and 5 being allocated to the most relevant. Therefore, in the study area, weights are fixed in the methodology, and the governing equation becomes as follows:

$$
\begin{aligned}
\text { DRASTIC index }= & 5 D_{\mathrm{r}}+4 R_{\mathrm{r}}+3 A_{\mathrm{r}}+2 S_{\mathrm{r}} \\
& +T_{\mathrm{r}}+5 I_{\mathrm{r}}+3 C_{\mathrm{r}} .
\end{aligned}
$$

The necessary information needed to run the model was available and inferred for the study area. Data analyses and model implementation were performed using the GIS software. Values of the parameters used in the aforementioned method are essentially derived from monitoring gauges, hydrogeological field surveys, including water level measurements, pumping tests and soil analyses, as well as remote-sensing studies. A database was established in order to input the collected data into ArcView GIS (9.2), which offers the ability to store, manipulate and analyse data in distinct formats and at different scales (Rahman 2008; Voudouris 2009; Sener et al. 2009). Once in the database, it is then possible to register all data as data layers with a common coordinate system and manipulate them to produce thematic maps.

\section{Results and discussion}

\subsection{DRASTIC model parameters}

The seven DRASTIC parameters were calculated as data layers as follows:

- The value of variable depth to the water (D) for the NSSA in The El-Bahariya Oasis was collected from 97 wells information between 2007 and 2011. Based on the constructed depth to groundwater rating map (figure 13), the value of variable D ranges from less than 1.5 to more than 30.4 $\mathrm{m}$. In general, higher water levels indicate that there is a greater chance for the contaminants to reach the groundwater table.

- Net recharge (R) is the total quantity of water infiltrate from the ground surface to the aquifer on an annual basis. Leaching and transport of pollutants from the surface due to the rainfall that infiltrates through the vadose zone are very important parameters in terms of aquifer vulnerability. The variable $\mathrm{R}$ was calculated from rainfall data and coefficients of infiltration of geological formations based on the soil type and lithology. As a result, net recharge in the study area is less than $50.8 \mathrm{~mm} /$ year with rating (Rr) equal to 1 .

- The data for aquifer material (A) was collected from the geological map, available hydrogeological cross sections, and drilled well logs data. According to this information, the NSSA media in El-Baharyia Oasis is mainly composed of clastic sediments of fine to medium sandstone with darkish grey shale intercalations, with rating equal to 6.

- Soil media (S) plays an important role in the net recharge of an aquifer, with the presence of coarse materials increasing infiltration and therefore, also pollution potential. Based on available soil maps and grain size analysis of borehole samples, the predominant soil types in the different parts of the El Baharyia Oasis are sand with shale intercalations and shale with fine sand, with a rating equal to 9 .

- The variable topography $(\mathrm{T})$ was obtained via elevation points, depending on the digital elevation model (ASTER DEM) with a high resolution of $30 \mathrm{~m}$ using ArcGIS 10.1 (figure 14). This parameter likelihood of a pollutant to be transported by runoff or remain on the ground where it may infiltrate the surface. The topography of El-Baharyia Oasis is, for the most part, a comparatively flat plain where slopes are relatively 


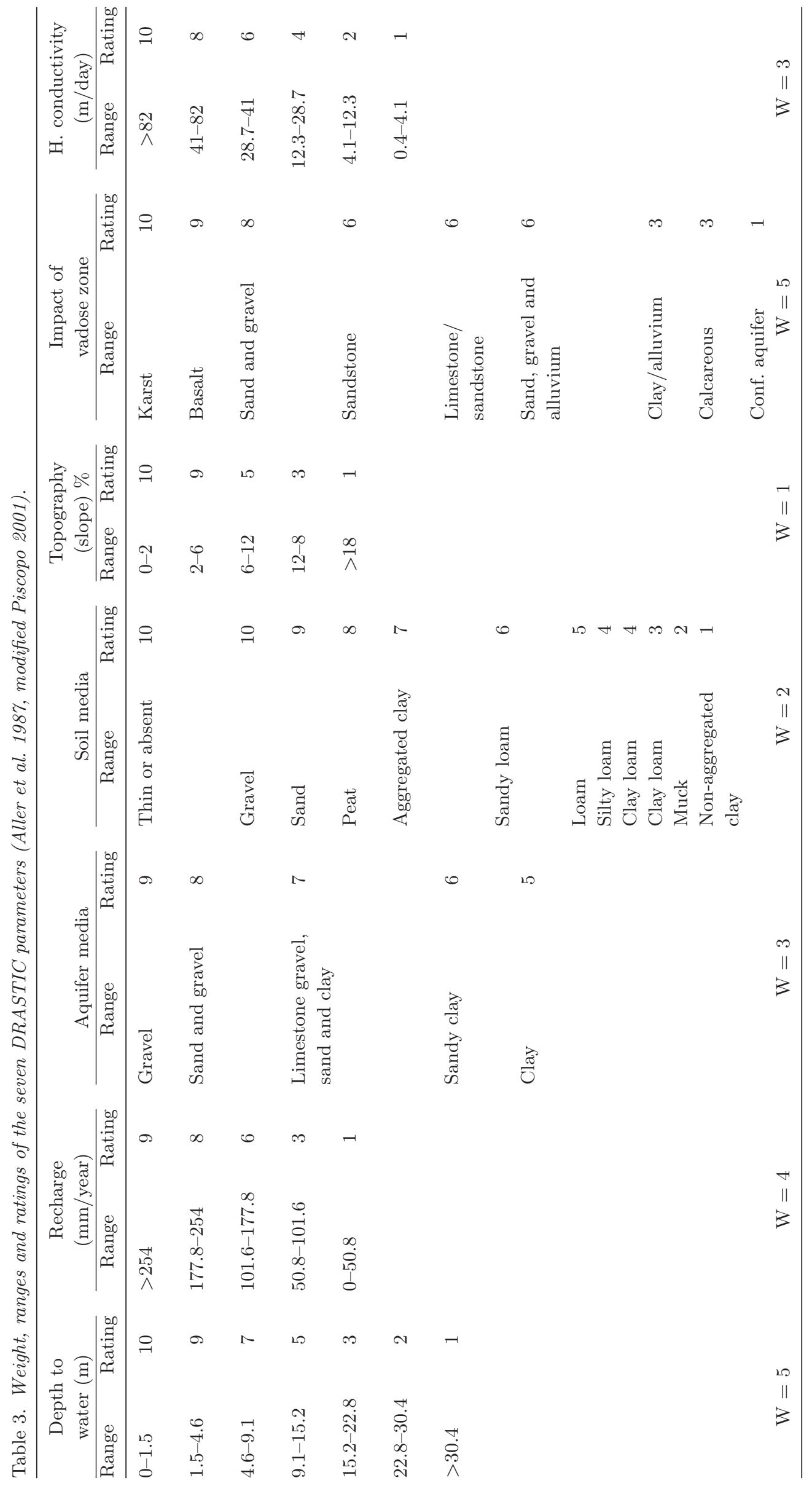




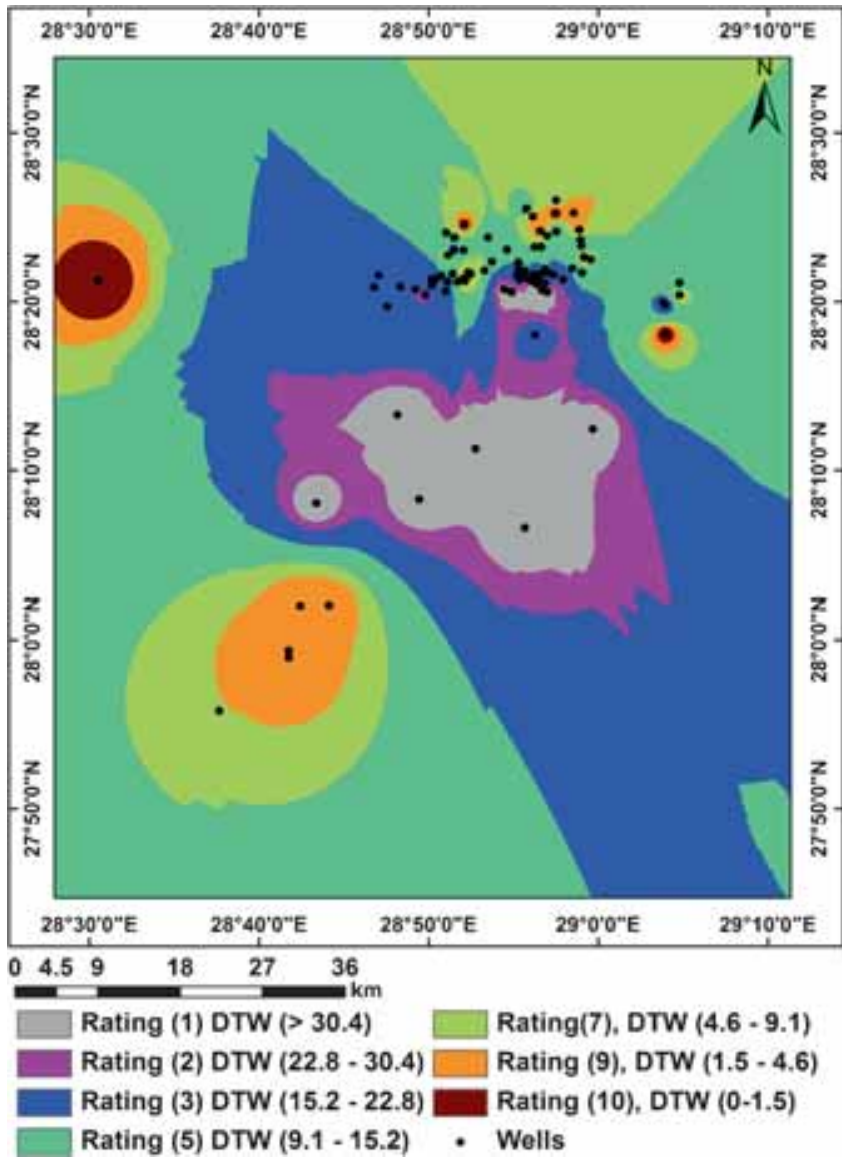

Figure 13. Depth to groundwater table rating map.

shallow (range 2-6\%), although some in a small area in the northwestern and southeastern parts reach almost $12 \%$.

- The vadose zone (I) is the unsaturated zone of subsoil above the water table and plays an important role in the percolation of surface flow. It also determines the pathway and concentration of a pollutant. In the study area, the evaluation of variable I was based on the data from drilling reports of wells. The vadose zone is composed of sandy clay with a rating equal to 3 .

- The value of hydraulic conductivity (C) is controlled by the properties of the aquifer and determines the rate of groundwater movement in the saturated zone. As hydraulic conductivity increases, the velocity of groundwater increases as well; the speed at which pollutants are transported also increases, causing rising aquifer vulnerability. In the concerned area, the variable $\mathrm{C}$ was calculated from pumping test data and ranges between 0.4 and $28.7 \mathrm{~m} /$ day; the rating distribution map is shown in figure 15 .

\subsection{DRASTIC index and aquifer vulnerability}

The latest DRASTIC index was determined by summing each DRASTIC thematic parameter. All

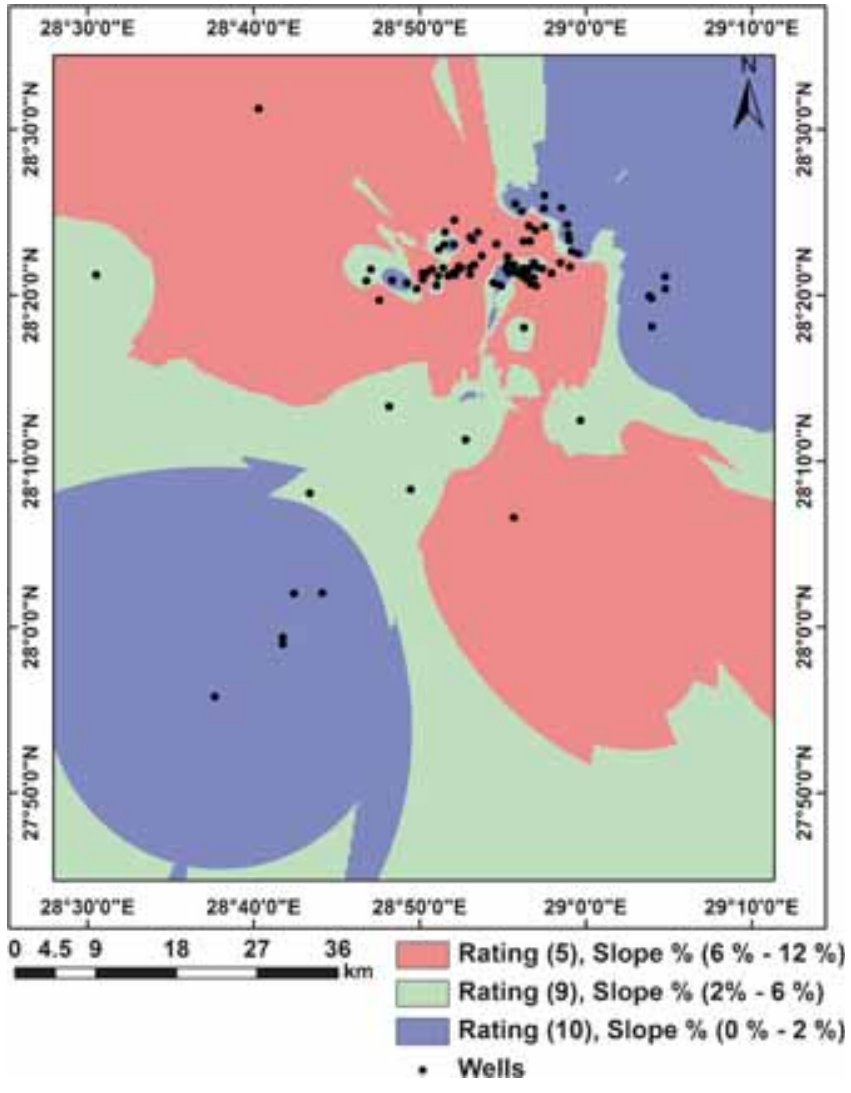

Figure 14. Slope rating map.

of the included parameters have been multiplied by its designated weighting factor, and then the concluding intrinsic vulnerability map was generated, as shown in figure 16 . The values of the DRASTIC vulnerability index was found to vary across the study, ranging between 66 and 121 . These values were classified into four classes; namely, very high (>120), high (1001-20), medium (80-100) and low $(<60)$. The regions that reflect the 'high' and 'very high' categories are more vulnerable to pollution and consequently, need to be managed more closely. These weights assigned are comparative; meaning an area with a 'low' pollution risk may still be vulnerable to groundwater contamination, although its vulnerability is less than the vulnerability of sites with high DRASTIC ratings. The vulnerability map of the NSSA in the ElBahariya Oasis (figure 16) shows that the majority of the concerned area is characterised by 'low' and 'medium' vulnerability levels, which are associated with a great depth to the water table especially in the central and southeastern parts of the ElBahariya Oasis. Therefore, these areas are promising for drilling water wells. 'Very high' and 'high' vulnerability levels are located in the northeastern (near Al Bawiti area) and western parts of the area. This situation is caused by small depth-to-water potentiated by the presence of sandstone, marl and alluvial rocks, all of which help to increase the 


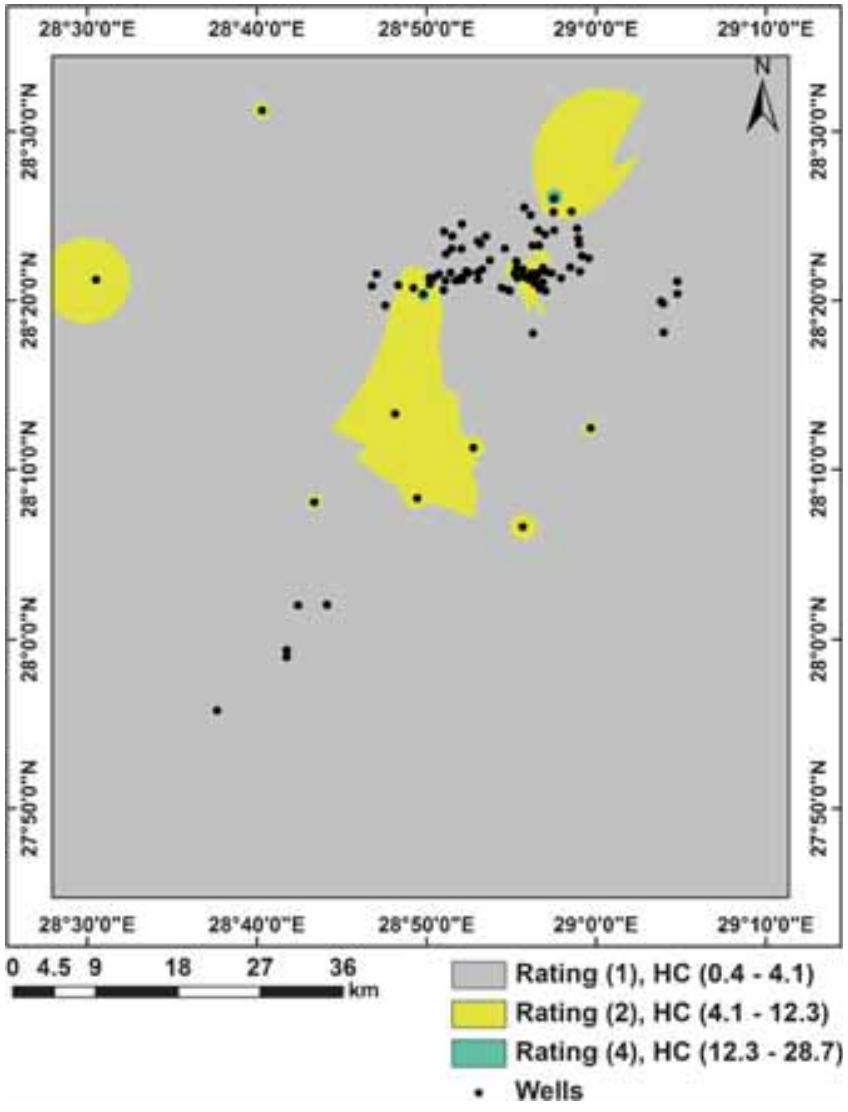

Figure 15. Hydraulic conductivity rating map.

infiltration water into the aquifer as well as increase agricultural activity and location of wastewater disposal in this region, which adds to groundwater pollution. However, in order to avoid groundwater contamination, special attention must be paid to the area with 'high' and 'very high' groundwater vulnerability, and risk assessment is necessary for land use and industrial development. Furthermore, geologic structures are very important factors in the vulnerability assessment, although such factors are not well reflected in a normal vulnerability assessment in this study. Higher vulnerability classes are expected along rock weak zones, allowing pollutants to move more easily, thus increasing the vulnerability of the groundwater (Al-Fawwaz 2010). Most of the geological structures in the study area are composed of faults, joints, fractures, straight course of dry streams and folds. Accordingly, the vulnerability map can be modified after introducing the effects of the fault system, which will be taken into account in the other research.

\subsection{Model validation}

A TDS distribution map was generated using the values of Total Dissolved Solids obtained from the El-Bahariya Oasis (2011) (figure 17). This map was categorised into eight, with TDS values ranging from

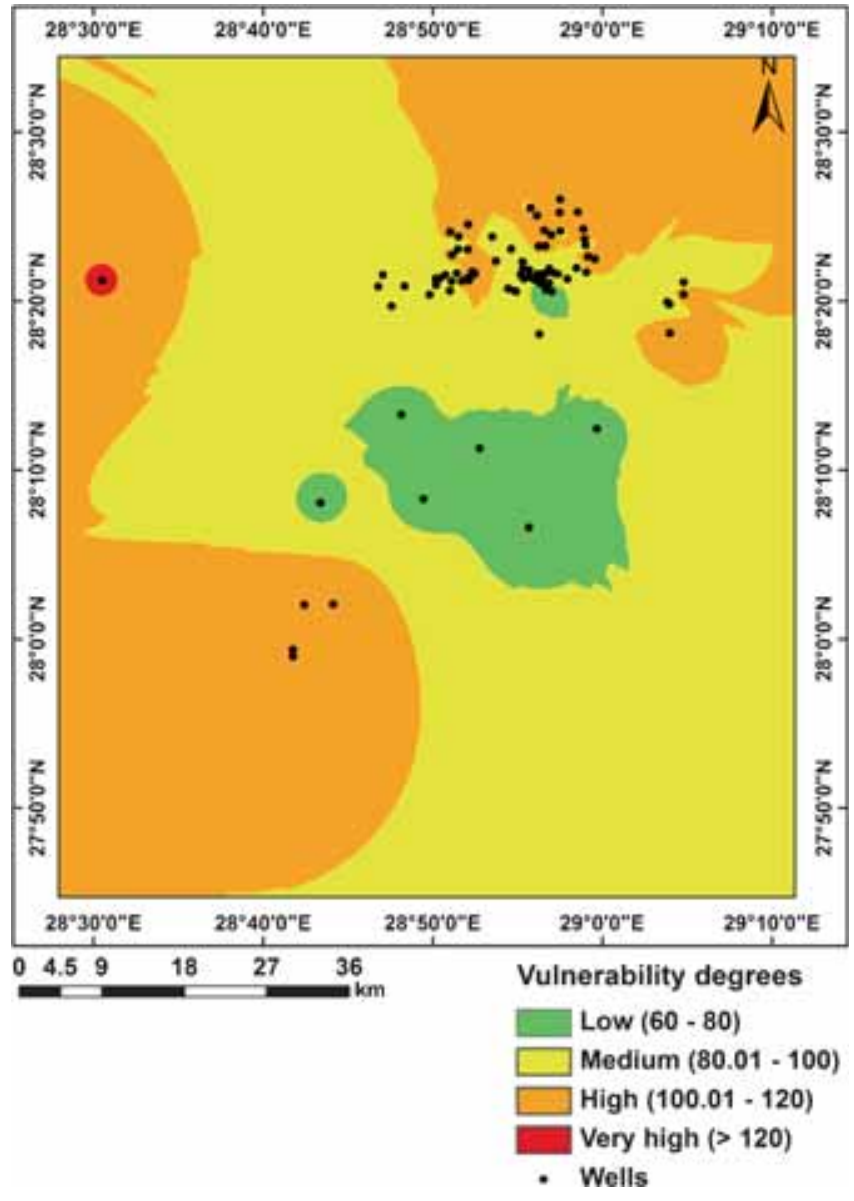

Figure 16. Vulnerability map of the NSSA.

160 to $505 \mathrm{mg} / \mathrm{l}$. The overlap between the DRASTIC vulnerability map (figure 16) and the TDS distribution map (figure 17) shows that the areas where high values of TDS have been detected correspond with those areas with higher DRASTIC ratings, especially in the north-eastern portion of the concerned area (near Al Bawiti area). This is due to the significant increase in agricultural activity spatially in the northern part of the oasis and the small depth of the water table, as well as the natural drainage capacity of the deep sandy soil profiles. All of these causes help to increase the infiltration of the excess irrigation water into the aquifer which allows the salinity of the groundwater to increase. From the above results, it can be concluded that the spatial correlation between groundwater vulnerability assessment using DRASTIC method and TDS distribution is relatively good. Finally, a Decision Support System (DSS) could be developed in which different factors, e.g., irrigation type, crop unit, types of fertilizers and water consumptions, are collected together to create a more comprehensive tool in order to define suitable land use and groundwater quality protection zones. Furthermore, the central and southeastern portions of the concerned 


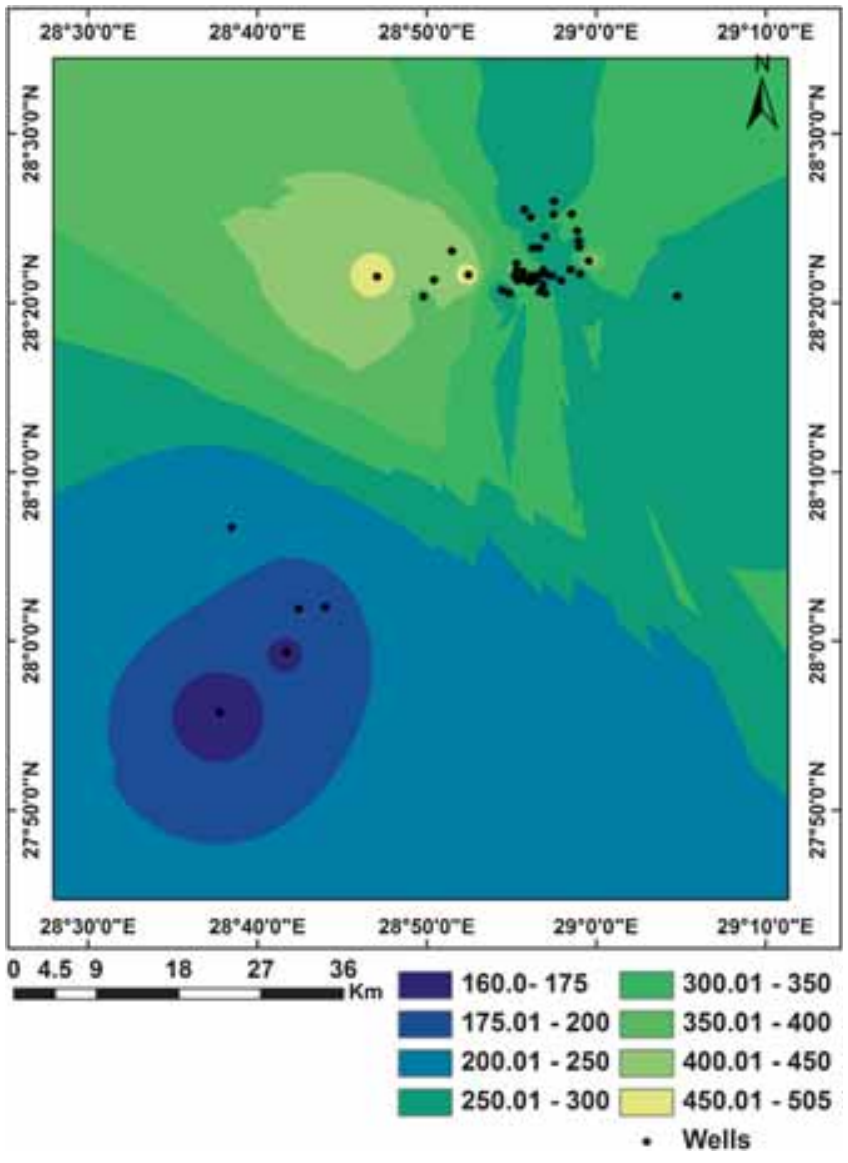

Figure 17. Total dissolved solids (TDS) distribution map of the NSSA.

area are promising for agriculture expansion by drilling new water wells, hence the priority of groundwater quality and potentiality increase in these areas, as well as the vulnerability decreases. The societal application of this study indicated that, care should be taken when allocating land uses in the study area. This is because any allocation that is not based on the vulnerability evaluation will not satisfy the criteria of groundwater protection.

\section{Conclusions and recommendations}

In the El-Bahariya Oasis, the Nubian Sandstone Aquifer (NSSA) forms a unique water resource for all human activities, generally containing fresh water. It is built up of continental clastic sediments of sandstone with shale and clay intercalations with thickness ranging from $317 \mathrm{~m}$ in the southwest to more than $1000 \mathrm{~m}$ in the northwest. Hydrogeologically, the groundwater of the NSSA exists under confined conditions with a flow directed from the southwest to the northeast of the oasis as a general flow, while in the northern sector it flows from the east and west to the Al Bawiti area as a result of intensive groundwater extraction in this area. On the other side, the flow direction in the southern sector is in the north-west to south-east direction, which clearly coincides with the drainage networks of the study area. The values of transmissivity of the NSSA ranged from 190.89 to $1750 \mathrm{~m}^{2}$ /day with a mean value of $970.45 \mathrm{~m}^{2} /$ day, while the hydraulic conductivity ranged from 1.12 to $24.9 \mathrm{~m}$ /day with a mean value of $13.1 \mathrm{~m} /$ day. Unfortunately, the groundwater reserves of the NSSA in The El-Bahariya Oasis are being attention. So, the integrated groundwater vulnerability assessment is essential for sustainable development. A trial was made to evaluate the groundwater vulnerability in the study area by the application of the powerful DRASTIC model and GIS techniques. The results of the used model indicate the following:

1. The northeastern and western parts of the NSSA are dominated by 'High' vulnerability classes.

2. The northwestern and south-eastern parts are characterised by 'Medium' vulnerability classes.

3. The elevated central part of the study area displayed 'Low' aquifer vulnerability.

4. The vulnerability map shows a relatively higher risk imposed on the northeastern part of the NSSA due to the high pollution potential of intensive cultivation.

5. Depth-to-water, topography and hydraulic conductivity parameters were found to be more effective in assessing aquifer vulnerability.

6. The areas where high values of TDS have been detected correspond with those with higher DRASTIC ratings, especially in the northeastern portion of the concerned area.

According to the results of the present research, further scope of work and recommendations should be taken into account as follows:

- In order to get better DRASTIC and other mathematical models, which deal with groundwater, an accurate relationship between the geologic structures (lineaments) and hydrogeological setting of the study area should be clarified.

- The groundwater vulnerability map of the NSSA could potentially be used by local authorities and decision makers in order to prevent the pollution and also to help the planners in selecting the sites of further reclamation areas in El-Bahariya Oasis.

- Observation and test wells are required to have continuous monitoring of the groundwater levels in El-Bahariya Oasis.

- The concentration of the drilling of wells in the central, northwestern and southeastern parts of the study area, with an interval distance, not be less than $1 \mathrm{~km}$ between each two successive wells, 
in order to minimise the interference drawdown between wells, especially when operating them simultaneously.

- Minimising the drilling of wells in the northeastern and western parts of the NSSA.

- Good drainage system should be constructed to protect the old and new reclaimed cultivated lands from destruction, by saving more water and preventing return flow of irrigation water as well as the waterlogging.

- Geologic structures are very important factors in the vulnerability assessment, so the effects of the fault system should be present in the final vulnerability map in the DRASTIC index.

- It is of utmost importance to ensure sustainable management of the fragile water resources in the concerned area.

- Public awareness is an effective tool to protect groundwater, as human activities form the main threat of polluting groundwater.

\section{References}

Al-Fawwaz M 2010 Role of the geologic structures on the aquifers vulnerability in arid areas: Case study from Swaqa-Ghabawi/Jordan; Jordan J. Civ. Eng. 4(2) 132154.

Aller L, Bennett T, Lehr J H, Petty R J and Hackett G 1987 DRASTIC: A standardized system for evaluating ground water pollution potential using hydrogeologic settings; EPA-600/2-87-035, National Water Well Association, Dublin, Ohio / EPA Ada. Oklahoma, 641p.

Alwathaf Y and El Mansouri 2011 Assessment of aquifer vulnerability based on GIS and ARCGIS methods: A case study of the Sana'a Basin (Yemen); doi: 10.4236/jwarp. 2011312094.

CEDARE (Centre for Environment and Development for Arab Region and Europe) 2001 Regional strategy for the utilization of the Nubian Sandstone Aquifer System; Cairo, V.I, II and III.

Civita M 1994 Le carte della vulnerabilità degli acquiferi all'inquinamento; Teoria e pratica, Pitagora editrice, Bologna, 325p.

Diab M S 1972 Hydrogeological and hydrochemical studies of the Nubian sandstone water-bearing complex in some localities in United Arab Republic; PhD Thesis, Assiut University, Egypt.

El Bastawesy M, Faid A and El Gammal S A 2010 The quaternary development of tributary channels to the Nile River at Kom Ombo area, Eastern Desert of Egypt, and their implication for groundwater resources; Hydrol. Process 24 1856-1865.

El Bastawesy M, Ali R, Faid A and El Osta M M 2013 Assessment of waterlogging in agricultural megaprojects in the closed drainage basins of the Western Desert of Egypt; Hydrol. Earth Syst. Sci. 17 1493-1501.

El Hossary M 2013 Ensuring sustainable development via groundwater management (case study: El-Bahariya Oasis); J. Am. Sci. 9(6) 6-13.

Euro and Pacer C 1983 Regional development plan for New Valley; Arab Republic of Egypt; Vols. 1 (Main Report) and 2 (Soils and Groundwater).

Ezzat M A 1974 Groundwater series in the Arab Republic of Egypt; Exploitation of groundwater in El-Wadi El-Gedid project area, General Desert Development Authority, Ministry of Irrigation, Cairo.

Hamdan M 2012 Multivariate statistical analysis of geochemical data of groundwater in El-Bahariya Oasis, Western Desert, Egypt; Res. J. Environ. Earth Sci. 4(6) 665-667.

Hamdan M and Sawires F 2013 Hydrogeological studies on the Nubian sandstone aquifer in El-Bahariya Oasis, Western Desert, Egypt; Arab. J. Geosci. 6(5) 1333-1347, doi: 10.1007/s12517-011-0439-8.

Himida I H 1964 Artesian water of the oases of Libyan Desert in U.A.R; Ph.D. Thesis, M.G.R.U Moscow (Russian language).

Karnieli A, Meisels A, Fisher L and Arkin Y 1996 Automatic extraction of geological linear features from digital remote sensing data using a Hough Transform; Photogramm. Eng. Rem. S. 62 525-531.

Khalifa R M 2006 Study of groundwater resources management in El-Bahariya Oasis; PhD Thesis, Faculty of Science, Alexandria University, pp. 226.

Lee S 2003 Evaluation of waste disposal site using DRASTIC system in southern Korea; Environ. Geol. 44(6) 654-664.

Polemio M, Dragone V and Limoni P 2009 Monitoring and methods to analyse the groundwater quality degradation risk in coastal karstic aquifers (Apulia, southern Italy); Environ. Geol. 58(2) 299-312.

Margat J 1968 Vulnerabilite des mappes d'eau souterraine a la pollution; Orleans: BRGM.

Ministry of Public Works and Water Resources 1998 Hydrogeology of deep aquifers in the Western Desert and Sinai; Water Policy Reform Program, International Resources Group Winrock International, Nile Consultants, Report No. 10, http://iwrm2eg.org/report/ Epiqreport/Report10APRP.pdf.

Mostafa M and Zakir F 1996 New enhanced techniques for azimuthal analysis of lineaments for detecting tectonic trends in and around the Afro-Arabian Shield; Int. J. Remote Sens. 17 2923-2943.

Murray K S and Rogers D T 1999 Groundwater vulnerability, Brownfield redevelopment and land use planning; J. Environ. Plann. Manag. 42(6) 801-810.

Parsons R M 1962 Bahariya and Farafra areas, New Valley project, Western Desert of Egypt; Final Report, Egyptian Desert Development Organization, Cairo.

Piscopo G 2001 Groundwater vulnerability map, explanatory notes, Castlereagh Catchment; NSW Department of Land and Water Conservation, Australia.

Polemio M, Casarano D and Limoni P P 2009 Karstic aquifer vulnerability assessment methods and results at a test site (Apulia, southern Italy); Nat. Hazard. Earth Sci. 9(4) 1461-1470.

Prior J C, Boekhoff J L, Howes M R, Libra R D and VanDorpe P E 2003 Iowa's groundwater basics.

Rahman A 2008 A GIS DRASTIC model for assessing groundwater vulnerability in shallow aquifer in Aligrah, Indaia; Appl. Geogr. 28 32-530.

RIGW (Research Institute for Groundwater) 2010 Hydrogeological map of El-Bahariya Oasis; Scale 1:100,000 Project, Hydrogeologcal maps of the Western Desert Development Areas, Egypt, Int. Report, RIGW, Egypt.

Sener E, Sener S and Davraz A 2009 Assessment aquifer vulnerability based on GIS and DRASTIC methods: A case study of the Senirkent - Uluborlu basin (Isparta, Turkey); Hydrogeol. J. 17 2023-2035.

Shukri N M 1954 Remarks on the geological structures of Egypt; Bull. Soc. Geogr. D'Egypt. 27 65-82.

SNIFFER (Scotland and Ireland Forum for Environmental Research) 2004 Development of a groundwater vulnerability 
screening methodology for the water framework directive; Project report code WFD 28, September 2004, Edinburgh.

Theis C V 1935 The relation between the lowering of the piezometric surface and the rate and duration of discharge of a well using groundwater storage; Am. Geophys. Union Trans. 16 519-524.

UNESCO 1998 Summary and recommendations of Int. Conf. on World Water Resources at the beginning of the 21st century 'Water: A looming crisis'; Paris, France.
US EPA 1985 DRASTIC; A standard system for evaluating groundwater potential using hydrogeological settings; Ada, Oklahoma WA/EPA Series 163.

Voudouris K 2009 Assessing groundwater pollution risk in Sarigkiol basin, NW Greece; In: River Pollution Research Progress (eds) Gallo M and Herrari M, Nova Science Publishers Inc., Chapter 7, pp. 265-281.

Zakir F, Qari M and Mostfa M 1999 A new optimizing technique for preparing lineament density maps; Int. J. Remote Sens. 20 1073-1085.

MS received 4 December 2015; revised 30 April 2016; accepted 12 May 2016

Corresponding editor: Subimal GHosh 